\section{Primary Hypertrophic Osteoarthropathy: An Update on Patient Features and Treatment}

\section{To the Editor:}

Hypertrophic osteoarthropathy (HO) is a disorder characterized by changes to the skin and bones, and occurs either in a rare familial primary form [primary hypertrophic osteoarthropathy, (PHO)], also called pachydermoperiostosis (PDP), with a 9:1 male:female prevalence ratio, or more commonly secondary to an underlying pathology ${ }^{1}$. Key features include digital clubbing, periostosis with bone and joint enlargement, and skin changes, such as pachydermia, abnormal furrowing, seborrhea, and hyperhidrosis. Specific developmental abnormalities have been found in some patients with PHO, such as wide cranial sutures, Wormian bones, and patent ductus arteriosus ${ }^{2}$. In adults, when all major clinical features are present, $\mathrm{PHO}$ is relatively easy to diagnose. However, for the pediatrician, who often has to contend with an incomplete clinical presentation ${ }^{3}$, diagnosis may be a challenge. The discovery of mutations in 2 prostaglandin pathway genes HPGD and SLCO2A1 has clarified the autosomal recessive inheritance [Mendelian Inheritance in Man (MIM) \#259100, MIM \#614441] of this genetically heterogeneous condition ${ }^{4,5,6,7}$.

Here we present 4 previously undescribed patients who exemplify the gene-dependent presentations of $\mathrm{PHO}$ and provide diagnostic and treatment advice.

The subjects' written consent was obtained in conformance to the Declaration of Helsinki.

Key clinical features are listed in Table 1 . Secondary causes of $\mathrm{HO}$ were excluded $^{8}$, and DNA sequence analysis (Supplementary Data available online at jrheum.org) confirmed the clinical diagnoses of PHO/PDP.

Case Report. Patient 1. A 20-year-old male patient had begun limping at the age of 14 months. At 3 years old, chronic arthritis of both knees was investigated by arthroscopy, with nonspecific chronic synovial inflammation at biopsy. Oligoarticular juvenile idiopathic arthritis (JIA) was diagnosed, and the patient was treated with nonsteroidal antiinflammatory drugs (NSAID), with clinical improvement. At age 5, coarse facies was noted. Tests for autoimmune diseases and mucopolysaccharidosis were normal. In the following years, the frequent relapses with arthritis required synovectomy, intraarticular steroid injections, immunosuppressive therapies [sulfasalazine (SSZ) and then methotrexate (MTX)], and tumor necrosis factor- $\alpha$-blocking agents (etanercept and adalimumab), with modest efficacy. From the age of 12 years, "watch-glass" nails and digital clubbing started to develop (Supplementary Figure 1 available online at jrheum.org), associated with a worsening pachydermia and furrowing of the forehead, leading to the clinical suspicion of PHO. The diagnosis was supported by elevated prostaglandin E2 (PGE2) levels (Supplementary Table 1 available online at jrheum.org) and by sequencing $H P G D$, which identified 2 reported heterozygous mutations ${ }^{2,4}$ (Table 1; Supplementary Figure 2 available online at jrheum.org). High-dose therapy with NSAID (ibuprofen $30 \mathrm{mg} / \mathrm{kg} /$ day) was started and is currently maintained, with clinical improvement but incomplete recovery.

Patient 2. A 21-year-old male patient was first admitted at age 13 because of isolated swelling and pain in the knees. This was diagnosed as oligoarticular JIA and treated with local steroid injections, and afterward with NSAID and SSZ because of persisting arthritis. Arthroscopy with biopsy and synovial fluid analysis confirmed nonspecific chronic synovitis. In the following years, the extension of the disease to the wrists, hips, ankles, and spine led to the use of MTX $\left(15 \mathrm{mg} / \mathrm{m}^{2} /\right.$ week) and NSAID (diclofenac 2 $\mathrm{mg} / \mathrm{kg} / \mathrm{day}$ ), with low efficacy. At age 18 , the patient started to develop severe aplastic anemia, requiring multiple transfusions, and thrombocytopenia, progressively associated with mild leukopenia (Figure 1). Bone marrow examination showed hypocellularity $(<5 \%$ to $40 \%)$, trilinear hematopoiesis with dyserythropoiesis, and moderate reticular fibrosis. Maintenance therapy of prednisone (PRED) $35 \mathrm{mg} /$ day was started and then gradually tapered. Hyperhidrosis and thickening of the skin with cutis verticis gyrata and seborrhea also became increasingly evident (Supplementary Figure 3 available online at jrheum.org). No digital clubbing was observed. PHO was suspected, and elevated PGE2 (Supplementary Table 1 available online at jrheum.org) and DNA sequencing confirmed this diagnosis. Compound heterozygosity for 2 nonsense mutations in SLCO2A1 was found: c.754C >T (p.R252X), previously described ${ }^{9}$, and c.794C $>\mathrm{G}$ (p.S265X), which was novel (Table 1; Supplementary Figure 3 available online at jrheum.org). The patient continued receiving ibuprofen $400 \mathrm{mg} 3$ times per day, combined with low-dose steroid therapy (PRED $10 \mathrm{mg}$ /day) for myelofibrosis. The hematological picture improved dramatically, achieving complete normalization. The patient had no further joint relapses, but followup radiographs of the hands, knees, and ankles showed metacarpal and fibular bilateral periostosis (Supplementary Figure 4 available online at jrheum.org). Generalized hyperhidrosis required oxybutynin $2.5 \mathrm{mg} 3$ times per day, with great efficacy. Considering the stabilization of the rheumatological and hematological picture, and the risk of worsening thrombocytopenia, NSAID were stopped and used again only in the last year for episodes of back pain.

Patient 3. A 15-year-old girl was first evaluated at the age of 9 for arthralgias in the knees, back, and ankles. She also had hyperhidrosis and a history of delayed suture closure. Over time, more pronounced coarse facial features developed. At 11 years old, she had signs of active arthritis in the knees, hands, hips, and feet, with normal laboratory tests and radiographs. Only magnetic resonance imaging (MRI) showed chronic arthritis in the left wrist. Therapy with NSAID (indomethacin $1 \mathrm{mg} / \mathrm{kg} /$ day) was started, with remarkable improvement of joint involvement and pain relief. At 15 years old, the patient relapsed with arthritis of the knees, associated for the first time with digital clubbing, hyperhidrosis, and mild anemia. A brief period of MTX ( $15 \mathrm{mg} / \mathrm{m}^{2} /$ week) was tried with no effect. PHO was diagnosed through the genetic testing of $H P G D$, identifying the homozygous c.120delA mutation (Table 1). Indomethacin was doubled with significant clinical improvement, both in the joint and skin involvement. The dysmorphic features did not progress.

Patient 4. This male child was evaluated at the age of 2.5 years after preterm birth $(33+4$ weeks, birth weight $1700 \mathrm{~g})$ for swelling and stiffness of the knees, gradually followed by involvement of the ankles, toes, and hands. Throughout the course of his disease, he had required surgery for a patent ductus arteriosus and physical therapy, including helmet remodeling, in the first months of his life for brachy-plagiocephaly. Delayed suture closure and late motor development and speech/language were observed. Physical examination also identified hyperhidrosis of the hands. Blood tests including antinuclear antibody, rheumatoid factor and inflammatory markers, ultrasound scan of the skull, and MRI of the knees were normal. Treatment with NSAID (ibuprofen $20 \mathrm{mg} / \mathrm{kg} / \mathrm{day}$ ) was started with positive results. At 3 years, bony enlargement of the distal phalanges and a thickened skull were revealed by radiographs. At age 4, $\mathrm{PHO}$ was diagnosed by the identification of 2 compound heterozygous HPGD mutations: c.175_176delCT and the novel c.298T>C (p.W100R; Table 1; Supplementary Data and Supplementary Figure 5 available online at jrheum.org). The patient was treated with ibuprofen, initially at $20 \mathrm{mg} / \mathrm{kg} /$ day and subsequently as necessary, with a stable clinical pattern requiring therapy around 2-3 times a week.

Here we have described 4 patients with PHO/PDP with $H P G D$ or SLCO2A1 deficiency [OMIM\#259100, autosomal recessive primary hypertrophic osteoarthropathy (PHOAR) 1 and \#614441, PHOAR2, respectively].

Although mutations in either HPGD or SLCO2Al cause PHO/PDP, there are phenotypic differences associated with each gene exemplified in patients 1 and 2, who had mutations in $H P G D$ and SLCO2A1, respectively. Patient 1 developed initial symptoms much earlier than patient 2. The onset of PHO is usually before the age of 20 , but its biphasic incidence is now attributed to the genetic heterogeneity, with onset of symptoms in early childhood for HPGD patients and during puberty/early adulthood for SLCO2Al patients $^{5,6,9,10,11,12,13}$.

Patients with SLCO2A1 mutations, such as patient 2, have been

Personal non-commercial use only. The Journal of Rheumatology Copyright $\odot$ 2015. All rights reserved. 
Table 1. Patients' clinical features.

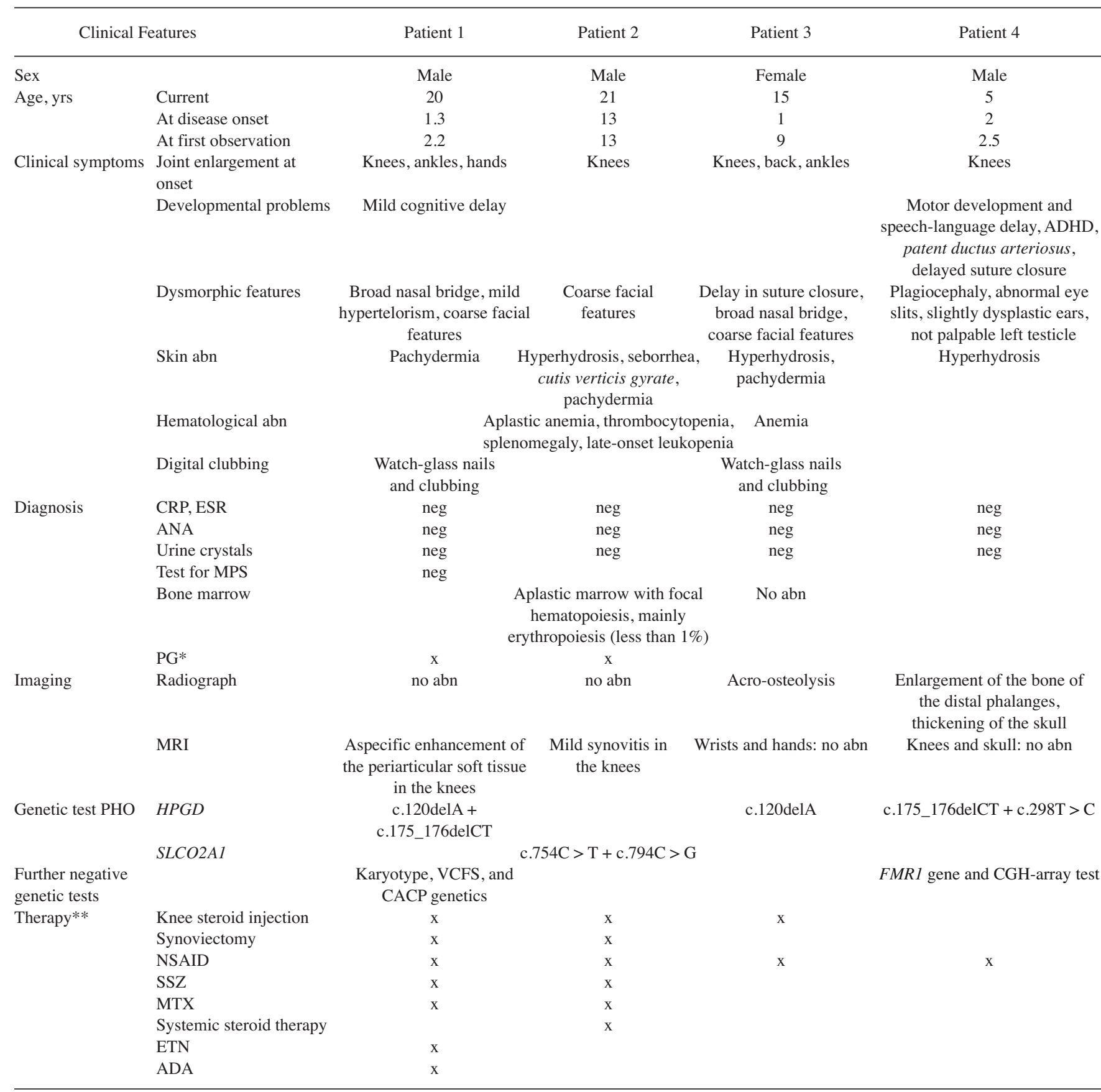

* For prostaglandin dosage see Supplementary Table 1 (available online at jrheum.org). ** For dose and period of therapy, see the text. ADHD: attention deficit hyperactivity disorder; abn: abnormalities; CRP: C-reactive protein; ESR: erythrocyte sedimentation rate; neg: negative; ANA: antinuclear antibodies; MPS: mucopolisaccaridosis; PG: prostaglandin; MRI: magnetic resonance imaging; PHO: primary hypertrophic osteoarthropathy; VCFS: velo-cardio-facial syndrome; CACP: Camptodactyly-Arthropathy-Coxa vara-Pericarditis; CGH: comparative genomic hybridization; NSAID: nonsteroidal antiinflammatory; SSZ: sulfasalazine; MTX: methotrexate; ETN: etanercept; ADA: adalimumab.

described as having more severe symptoms overall ${ }^{6,9,11}$, the presence of skin folds (as cutis verticis gyrata) ${ }^{5,12}$, and chronic anemia and/or pancytopenia, secondary to hypocellular myelofibrosis ${ }^{5,14,15}$. On the other hand, patients 3 and 4 exhibited delayed cranial suture closure that has led to the use of the term "cranio-osteoarthropathy". This has only been seen in patients with HPGD mutations $\mathrm{s}^{2,4,12,16}$.
The histories of our patients suggest approaches for clinical practice. For example, young children with swollen and painful joints and a history of patent ductus arteriosus, delayed closure of the cranial sutures, and fontanelles or Wormian bones should be investigated immediately for PHO because clubbing, periostosis, and skin changes might be absent. When $\mathrm{PHO} / \mathrm{PDP}$ is suspected, secondary causes have to be excluded. Blood and 
A.

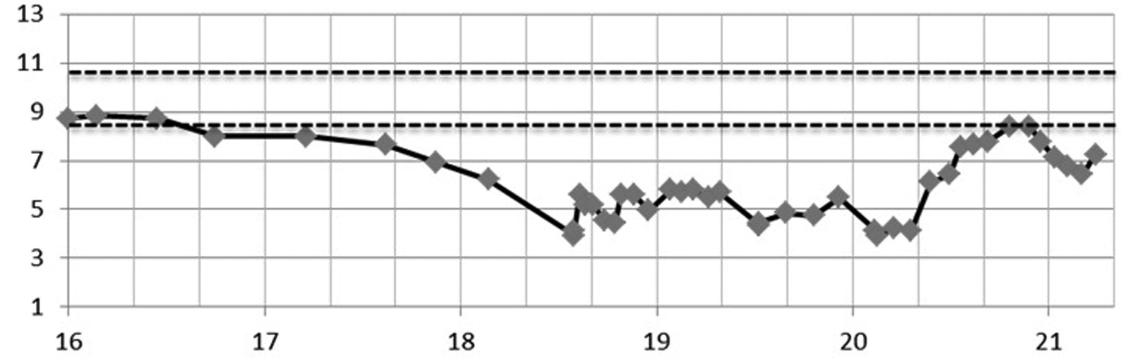

B.
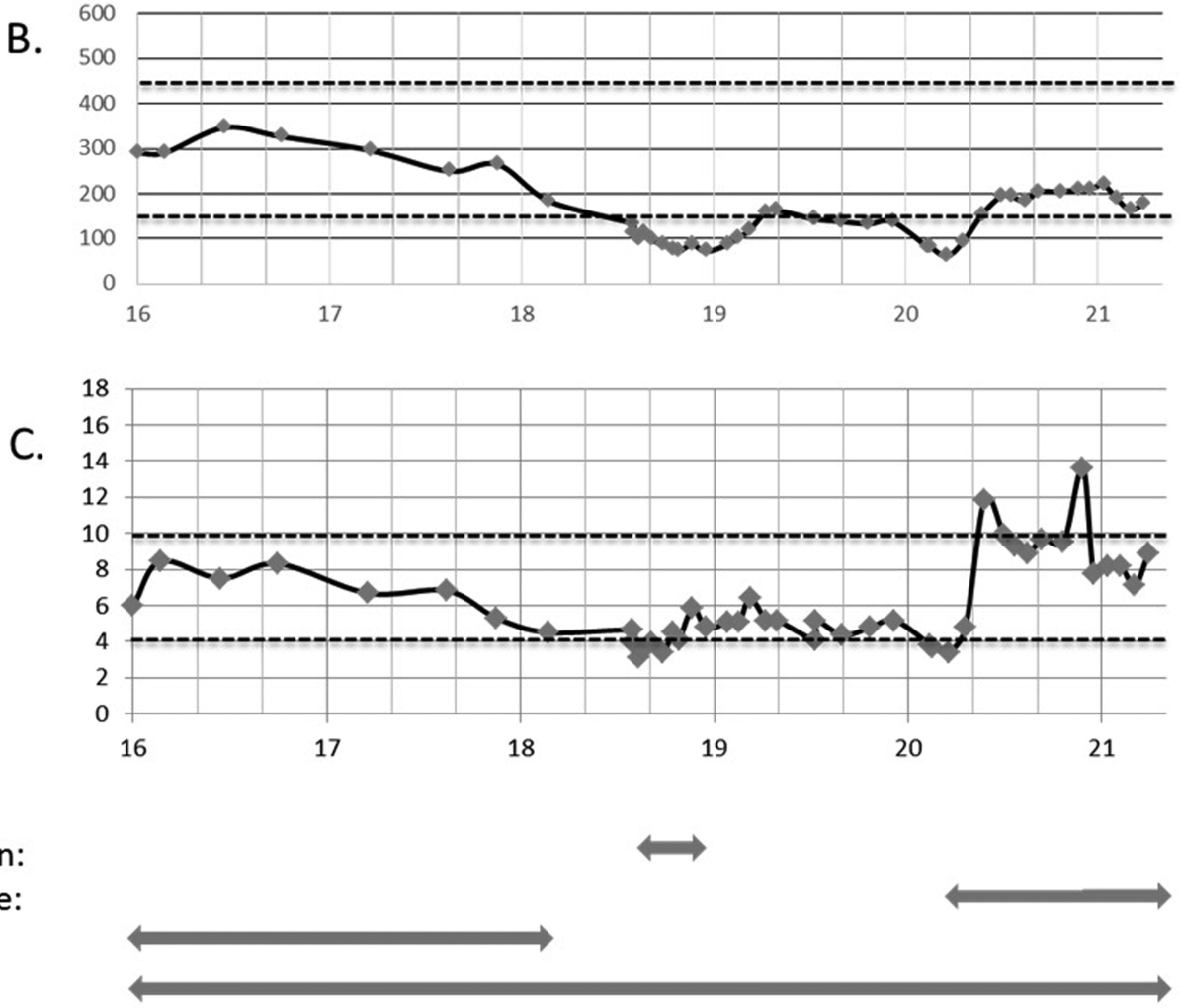

Transfusion:

Prednisone:

MTX:

NSAIDs:

Figure 1. Hemoglobin, platelet, and leukocyte patterns in Patient 2 over time. The level of (A) hemoglobin, (B) platelets, and $(\mathrm{C})$ leukocytes was monitored over 6 years. Normal ranges (areas between the dashed lines): hemoglogin: 8.6-10.7 mmol/1; platelets: $150-450 \times 10^{9} / 1$; and leukocytes: $4-10 \times 10^{9} / 1$.

early morning urine can be considered for prostaglandin measurement, but their detection is not feasible in all laboratories, and implications in differential diagnosis, followup, and treatment still need to be studied and standardized with age-related values ${ }^{13}$. In contrast, sequence analysis of both genes is simple and cheap, and therefore should be considered as an early investigation when $\mathrm{PHO} / \mathrm{PDP}$ is suspected because it can provide confirmation of diagnosis. The presence of chronic arthritis often leads to a diagnosis of JIA. Nevertheless, a patient with JIA, nonresponder to DMARD and biological therapies, and with a better response to NSAID, should be considered as having another disease and investigated for further clinical signs. Indeed, $H P G D$ and SLCO2Al patients usually experience some positive effects on joint pain and swelling while being treated with NSAID $^{5,12,16,17,18}$, but it is uncertain if either the use of indomethacin compared with ibuprofen could provide better results clinically, as for patient 3 , or if the phenotype of this patient is milder as a consequence of being female.

Myelofibrosis is a life-threatening complication; consequently, when germline SLCO2A1 mutations are detected, the patient should be followed up periodically for myelofibrosis. The use of steroids can produce hemato- logical improvement, but no effects on skin or digital clubbing, and longer-term treatment may help in symptom stabilization ${ }^{19}$. NSAID appear to be the best option for treatment, while other treatments can be evaluated individually, but support for their use is largely anecdotal ${ }^{20,21,22}$.

GABRIELLA GIANCANE*, MD, Department of Pediatric Immunology, University Medical Centre Utrecht (UMC), Utrecht, the Netherlands; CHRISTINE P. DIGGLE*, MD, School of Medicine, St. James's University Hospital, University of Leeds, Leeds, UK; ELIZABETH G. LEGGER, MD, Department of Pediatric Immunology, UMC; JANNEKE TEKSTRA, MD, Department of Rheumatology \& Clinical Immunology, UMC; BERENT PRAKKEN, MD, Laboratory for Translational Immunology, UMC; ARJAN B. BRENKMAN, MD, Department of Metabolic and Endocrine Diseases, UMC; IAN M. CARR, MD, School of Medicine, St. James's University Hospital, University of Leeds; ALEXANDER F. MARKHAM, BSc, PhD, MB, BS, DSc, FRCP, FRCPath, School of Medicine, St. James's University Hospital, University of Leeds; DAVID T. BONTHRON, MD, PhD, School of Medicine, St. James's University Hospital, University of Leeds; NICO WULFFRAAT, MD, PhD, Department

\section{Personal non-commercial use only. The Journal of Rheumatology Copyright $\odot$ 2015. All rights reserved.}


of Pediatric Immunology, UMC. *G. Giancane and C.P. Diggle contributed equally to this study. Supported in part by a grant from Cancer Research UK, MRC MR/L01629X/1, and a Wellcome Trust VIP award. Address correspondence to Dr. Gabriella Giancane, Department of Pediatric Immunology, University Medical Centre Utrecht, 3508 AB, Utrecht, the Netherlands.E-mail: gabriella.giancane@gmail.com, ggiancan@umcutrecht.nl

\section{ONLINE SUPPLEMENT}

Supplementary data for this article are available online at jrheum.org.

\section{REFERENCES}

1. Friederich N. [Archive for pathological anatomy and physiology and for clinical medicine]. [Article in French] Arch Path Anat 1868;43:83-7.

2. Seifert W, Beninde J, Hoffmann K, Lindner TH, Bassir C, Aksu F, et al. HPGD mutations cause cranioosteoarthropathy but not autosomal dominant digital clubbing. Eur J Hum Genet 2009; 17:1570-6.

3. Latos-Bielenska A, Marik I, Kuklik M, Materna-Kiryluk A, Povysil C, Kozlowski K. Pachydermoperiostosis-critical analysis with report of five unusual cases. Eur J Pediatr 2007;166:1237-43.

4. Uppal S, Diggle CP, Carr IM, Fishwick CW, Ahmed M, Ibrahim $\mathrm{GH}$, et al. Mutations in 15-hydroxyprostaglandin dehydrogenase cause primary hypertrophic osteoarthropathy. Nat Genet 2008;40:789-93.

5. Diggle CP, Parry DA, Logan CV, Laissue P, Rivera C, Restrepo CM, et al. Prostaglandin transporter mutations cause pachydermoperiostosis with myelofibrosis. Hum Mutat 2012;33:1175-81.

6. Seifert W, Kühnisch J, Tüysüz B, Specker C, Brouwers A, Horn D. Mutations in the prostaglandin transporter encoding gene SLCO2A1 cause primary hypertrophic osteoarthropathy and isolated digital clubbing. Hum Mutat 2012;33:660-4.

7. Zhang Z, Xia W, He J, Zhang Z, Ke Y, Yue H, et al. Exome sequencing identifies SLCO2A1 mutations as a cause of primary hypertrophic osteoarthropathy. Am J Hum Genet 2012;90:125-32.

8. Pineda C, Martínez-Lavín M. Hypertrophic osteoarthropathy: what a rheumatologist should know about this uncommon condition. Rheum Dis Clin North Am 2013;39:383-400.

9. Cheng R, Li M, Guo Y, Yao Y, Gao C, Yao Z. Three novel mutations in the SLCO2A1 gene in two Chinese families with primary hypertrophic osteoarthropathy. Eur J Dermatol 2013;23:636-9.

10. Zhang Z, He JW, Fu WZ, Zhang CQ, Zhang ZL. A novel mutation in the SLCO2A1 gene in a Chinese family with primary hypertrophic osteoarthropathy. Gene 2013;521:191-4.

11. Madruga Dias JA, Rosa RS, Perpétuo I, Rodrigues AM, Janeiro A Costa MM, et al. Pachydermoperiostosis in an African patient caused by a Chinese/Japanese SLCO2A1 mutation-case report and review of literature. Semin Arthritis Rheum 2014;43:566-9.

12. Tüysüz B, Yılmaz S, Kasapçopur O, Erener-Ercan T, Ceyhun E, Bilguvar K, et al. Primary hypertrophic osteoarthropathy caused by homozygous deletion in HPGD gene in a family: changing clinical and radiological findings with long-term follow-up. Rheumatol In 2014;34:1539-44.

13. Zhang Z, He JW, Fu WZ, Zhang CQ, Zhang ZL. Mutations in the SLCO2A1 gene and primary hypertrophic osteoarthropathy: A clinical and biochemical characterization. J Clin Endocrinol Metab 2013;98:923-33

14. Castori M, Sinibaldi L, Mingarelli R, Lachman RS, Rimoin DL, Dallapiccola B. Pachydermoperiostosis: an update. Clin Genet 2005;68:477-86

15. Fontenay-Roupie M, Dupuy E, Berrou E, Tobelem G, Bryckaert M. Increased proliferation of bone marrow-derived fibroblasts in primitive hypertrophic osteoarthropathy with severe myelofibrosis. Blood 1995;85:3229-38.

16. Bergmann C, Wobser M, Morbach H, Falkenbach A, Wittenhagen D, Lassay L, et al. Primary hypertrophic osteoarthropathy with digital clubbing and palmoplantar hyperhidrosis caused by 15-PGHD/HPGD loss-of-function mutations. Exp Dermatol 2011;20:531-3

17. Erken E, Köroğlu Ç, Yıldız F, Özer HT, Gülek B, Tolun A. A novel recessive 15-hydroxyprostaglandin dehydrogenase mutation in a family with primary hypertrophic osteoarthropathy. Mod Rheumatol 2015;25:315-21.

18. Diggle CP, Carr IM, Zitt E, Wusik K, Hopkin RJ, Prada CE, et al. Common and recurrent HPGD mutations in Caucasian individuals with primary hypertrophic osteoarthropathy. Rheumatology 2010;49:1056-62.

19. Ninomiya S, Hara T, Tsurumi H, Kanemura N, Kasahara S, Ogawa $\mathrm{Y}$, et al. Myelofibrosis successfully treated with prednisolone in a patient with pachydermoperiostosis. Intern Med 2011;50:2207-11.

20. Jojima H, Kinoshita K, Naito M. A case of pachydermoperiostosis treated by oral administration of a bisphosphonate and arthroscopic synovectomy. Mod Rheumatol 2007;17:330-2.

21. Warwas S, Specker C, Jäger M, Landgraeber S. Arthroscopic synovectomy and radiosynoviorthesis: a treatment option for recurrent arthritis symptoms in patients with pachydermoperiostosis. Reumatismo 2013;65:82-5

22. da Costa FV, de Magalhães Souza Fialho SC, Zimmermann AF, Neves FS, Werner de Castro GR, Pereira IA. Infliximab treatment in pachydermoperiostosis: a rare disease without an effective therapeutic option. J Clin Rheumatol 2010;16:183-4.

J Rheumatol 2015;42:11; doi:10.3899/jrheum.150364 